\title{
Politics across Generations: Family Transmission Reexamined
}

\author{
M. Kent Jennings University of California, Santa Barbara \\ Laura Stoker University of California, Berkeley \\ Jake Bowers University of Illinois, Urbana-Champaign
}

\begin{abstract}
We use longitudinal data incorporating three generations of Americans to reevaluate the character and consequences of political socialization within the family. Findings about parental influence based on youth coming of age in the 1990s strongly parallel those based on youth socialized in the 1960s. As expected on the basis of social learning theory, children are more likely to adopt their parents' political orientations if the family is highly politicized and if the parents provide consistent cues over time. The direct transmission model is robust, as it withstands an extensive set of controls. Early acquisition of parental characteristics influences the subsequent nature of adult political development.
\end{abstract}

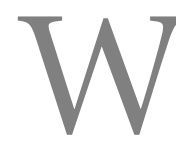

riting 40 years ago, Jennings and Niemi (1968) questioned the conventional wisdom about the role of parents in shaping the political character of their children. Working from the perspective of social learning theory and drawing on data collected independently from adolescents and their parents, they demonstrated high variability in the political similarity between parents and their children. Especially when judged against the expectations laid down by reliance on retrospective accounts of parental attributes, the results appeared to downgrade the direct transmission model, wherein parental attributes were passed on, wittingly or unwittingly, to their offspring. These outcomes seemed all the more surprising in view of the considerable overall aggregate congruence between the two generations.

Somewhat lost in the (over) generalizations flowing out of this and related research were a number of important qualifications. Transmission rates tended to vary in a systematic fashion according to type of political trait. The more concrete, affect-laden, and central the object in question, the more successful was the transmission. More abstract, ephemeral, and historically conditioned attributes were much less successfully passed on. Salience of the political object for the parents was an important conditioner of successful reproduction, as was perceptual accuracy on the part of the child (Acock and Bengston 1980; Percheron and
Jennings 1981; Tedin 1980; Westholm 1999). The presence of politically homogeneous parents, and other agents allied with the parents, enhanced the fidelity of transmission (Jennings and Niemi 1974, chap. 6; Tedin 1980). Contextual properties such as larger opinion climates (Jennings and Niemi 1974, 81-82, 161-62) and party systems (Westholm and Niemi 1992) also affected within-family consonance. These specifications and qualifications also lent support to social learning theory explanations of how children come to resemble their parents more in some respects than others. Although not in the tradition of the transmission model, but fully compatible with social learning theory, other inquiries have revealed the importance of communication patterns within the family in shaping the political make-up of the child (e.g., Tims 1986; Valentino and Sears 1998).

In this paper we return to the topic of intergenerational transmission informed by scholarship subsequent to the earlier research and enriched by the availability of additional data, as described below. We address four main questions, questions raised but not resolved by earlier work. In addressing these questions, we seek to contribute a fresher, more comprehensive understanding of intergenerational transmission, and of how early political socialization influences the dynamics of attitude formation and change over the life course. 
The first question is whether past findings about intergenerational transmission are cohort-specific. Virtually all studies of adolescents and their parents originated between the mid 1960s and the 1970s. In particular, the Jennings and Niemi (1968) findings were based on pairs formed from high school seniors of 1965, a cohort coming of age during the heights of the civil rights movement and the war in Vietnam and one that experienced a number of uncommon and dramatic events during adolescence and young adulthood. Given these considerations, it has been suggested that the findings from the mid-1960s may be cohort-centric, that preceding and succeeding cohorts would exhibit different patterns of relationships, presumably including more faithful political reproduction of their parents (e.g., Sears and Funk 1999). Testing for cohortcentrism requires a replication of the research with a subsequent cohort of parent-child pairs, one where the offspring were socialized under quite different historical and familial circumstances. We respond by comparing parentchild transmission levels for the original Jennings/ Niemi pairs with those for a new set of pairs, one where the children were coming of age in the mid 1980s to mid 1990s.

A second question concerns the circumstances under which parental influence is enhanced. Here we move beyond what transmission rates typically look like to consider processes that work to make transmission rates especially high or especially low. According to social learning theory, transmission success should vary according to the strength of cue giving and reinforcement on the part of the socializer. Previous research has typically evaluated this expectation by ascertaining if transmission rates are especially enhanced in highly politicized families. Our analysis revisits this question and adds a new perspective, capitalizing on the longitudinal design to evaluate how the over-time consistency of parental cue giving on specific political issues influences transmission success.

These first two questions stem from applying the standard transmission model, which views parentchild similarity as an outcome of social influence and learning processes operating within the home. These processes are assumed to rest on observational learning and its variants of modeling, imitation, and identification, all of which work to heighten reproductive fidelity along political lines. Yet parent-child agreement is not, itself, evidence that such transmission processes are operating. Children and parents may become politically similar because of other influences they share, including their socioeconomic circumstan- ces and their local political contexts. Our third question, then, is to what extent does the transmission model survive once these alternative sources of parentchild similarity are taken into account? To answer this question we estimate multivariate models of youth attitudes that introduce additional parent, child, and school-level contextual explanatory variables.

The final question we take up involves the longterm consequences of early political socialization. How does the early acquisition of political characteristics, via family transmission, influence the child's subsequent political development? Do those who leave home well-socialized differ later in life from those who do not? These are questions where the expectations are strong, but the existing evidence is weak. At a minimum, well-socialized youth should manifest more over-time continuity in their political orientations, withstanding the forces of change more than their less well-socialized counterparts. We evaluate this expectation by examining how patterns of political development over the adult life-span vary according to the success of parental transmission as of late adolescence.

\section{Study Design and Measures}

We draw on a portion of the longitudinal parentchild political socialization project carried out by the University of Michigan's Survey Research Center and Center for Political Studies (ICPSR study \#9553, \#4037, and \#3926). The original core of the project consisted of interviews with a national sample of 1,669 high school seniors from the graduating class of 1965, distributed across 97 public and nonpublic schools chosen with probability proportionate to size (Jennings and Niemi, 1974, Appendix). Subsequent surveys conducted in 1973, 1982, and 1997 resulted in a four-wave panel of 935 individuals, which represents an overall, unadjusted retention rate of $56 \% .^{1}$ During

\footnotetext{
${ }^{1}$ All respondents were interviewed face-to-face in 1965, as were the great majority in 1973 and 1982, when an abbreviated mailback questionnaire was used for remotely located individuals. In 1997 approximately one-half of the interviews were faceto-face and the other half by telephone. Respondent bias across the four waves appears to be slight. The crucial comparison is between the 935 four-wave panel respondents and the 734 respondents surveyed in the 1965 study who dropped out in one of the post-1965 waves. The former had slightly higher scores on measures of political involvement as of 1965 and were slightly more liberal. However, panel status never accounts for over $2 \%$ of the variation in the scores of explicitly political measures.
} 
the first three waves interviews were conducted with at least one parent, thereby enabling the construction of parent-child pairs as units of analysis. Altogether 636 pairs, based on Generations 1 (the parents) and 2 (their offspring), have survived over the course of the study. For convenience we will refer to these generations as G1 and G2, respectively. ${ }^{2}$

In addition to reinterviews with G2 in 1997, selfadministered data were obtained from G2's offspring aged 15 and older, i.e., Generation 3 (G3). A total of 769 out of a possible 1,435 respondents returned their questionnaires, for a response rate of $54 \%$. Pairing these respondents with their parents yielded a new set of parent-child pairs based on G2 and G3. Two important features distinguish these pairs from those based on the first two generations. First, in contrast to G2, but similar to G1, the third generation has a variable age range, with a mean of 23 and a standard deviation of 4.4. As described in more detail below, the age variation proves helpful for certain analytical purposes. It follows that G3, unlike G2, represents only a lineage cohort rather than a high school senior cohort. A second distinguishing feature is that whereas all of the earlier cases involved parents paired with a single child, some of the new cases include parents paired with two or more of their children. Overall, $32 \%$ of the new cases were based on parents paired with one child, $42 \%$ with two, $17 \%$ with three, and $4 \%$ with four. ${ }^{3}$

For the most part we use a core set of ten measures. Because of our longitudinal perspective, we are constrained by the availability of questions that were asked across all study waves. A thumbnail description of all of the measures follows. Many of these are standard measures found in the National Election Studies (NES) series. Detailed descriptions of the others are contained in the appendix.

Partisanship - Intergenerational transmission of partisanship has been a staple of scholars in the field of political socialization as well as electoral behavior and political parties. One of the indicators used here is the standard 7-point party identification measure running from Strong Democrat to Strong Republican. The second indicator, presidential vote choice, is

\footnotetext{
${ }^{2}$ Panel attrition from each generation and the absence of an initial parent interview account for the difference between the 935 four-wave panel members and the 636 parent-child pairs. The unadjusted retention rate from the original 1556 pairs is $41 \%$. $58 \%$ of the 636 parents are mothers and $42 \%$ are fathers.

${ }^{3}$ This feature raises the issue of whether the data should be weighted by number of children. We report the unweighted results, which turn out to be very similar to the weighted results.
}

based on the partisan direction of the vote cast in the election(s) most proximate to the survey date.

Political issues - A hallmark of the era in which the class of 1965 came of age was an emphasis on the doctrines of civil rights and civil liberties as stressed especially by the civil rights, free speech, and antiwar movements. Popular depictions of generation gaps evolved out of such movements. One indicator in this attitudinal domain consists of the respondents' racial attitudes, formed from their relative rating of blacks and whites on the $0-100^{\circ}$ feeling thermometer and their opinions on whether the government should ensure the racial integration of schools. For civil liberties one measure taps opinions on whether school prayer should be allowed. A second is and a two-item index that assesses the individual's tolerance of nonconformity based on whether communists should be allowed to hold local office and whether speeches against churches should be allowed. The sole indicator of traditional issues is the relative evaluations of big business and labor, as determined by placement on the feeling thermometer. ${ }^{4}$

Political trust-Of all the measures employed in the project, this one has undergone the most drastic change at the aggregate level, the relatively high scores once accorded the federal government having plummeted over time. To build a political trust index we used the standard five items also found in the NES instruments.

Political engagement-Although we have extensive participation histories for each generation, no 1965 entry for G2 members exists inasmuch as they were just finishing high school at the time. Consequently, we rely on two measures that are available throughout. One is the conventional self-report of political interest - of how often the individual thinks about what's going on in government- "most of the time, some of the time, only now and then, or hardly at all." A second indicator consists of a political knowledge index based on the number of correct answers to five factual questions about historical and contemporary figures or institutions-term for U.S. Senators, number of Supreme Court justices, partisanship of Franklin Delano Roosevelt, Marshall Tito's home country, and location of WW II concentration camps for Jews.

Religious orientations-Fundamental manifestations of family-influenced socialization involve religious

\footnotetext{
${ }^{4}$ Additional political issue questions were added to the survey after 1965 and are available for the G2-G3 analyses. We summarize the results for these additional measures when appropriate. The full set of analyses is available in the online appendix at http://journalofpolitics.org.
} 
identification, beliefs, and behavior (e.g., Glass, Bengston, and Dunham 1986). In order to see if the processes characterizing the results in the political realm are restricted or more generalizable, we employ a two-item index of religiosity, combining frequency of church attendance and belief in the inerrancy of the Bible. While nominally tapping religiosity, these two indicators also have strong political manifestations (e.g., Miller and Shanks 1996, chaps. 9-10).

\section{Parent-Child Correspondence across Generations}

We posited earlier that rates of political reproduction within the family observed in the parent-child pairs originating in the mid 1960s may have been attenuated due to the dramatic historical circumstances surrounding the coming of age of the younger generation (G2). By contrast, the period during which the third generation (G3) came of age, roughly the mid-1980s to the mid 1990s, was relatively calm, bracketed by President Ronald Reagan's second term and Bill Clinton's first term. To the degree that disruptive socio-political events work to undermine parent-child political similarity, pair correspondence would be expected to be higher for our second set of pairs (G2-G3). However, a counterargument can be marshaled. Since the earlier era, familial structures have altered considerably, with a rise in divorce rates, blended families, and single parent households. Based on the social learning principles of sustained cue giving and reinforcement, these changes in family structure would arguably result in lower pair correspondence. Then, too, a variety of marked innovations have occurred in communications media, most notably that of the Internet. These innovations may have worked to reduce the primacy of the family as a source of political socialization.

Even if we do not observe wholesale differences across periods in the extent of parent-child transmission, differences on specific attributes may appear. One strong possibility concerns the issues that were salient in the respective periods. Issues involving race and civil rights dominated politics in the mid1960s much more so than in the 1990s, whereas partisan controversies involving religion and morality were much more prominent in the latter period than the former. Because issues in the national spotlight are also likely to be salient within the home, we may find period differences in transmission that reflect the shifting political agenda. Another possibility concerns the parents' role in shaping their children's partisan attachments. Some scholars have suggested that parental influence has declined in recent years as ideological differences between the parties have become increasingly clear (e.g., Abramowitz and Saunders 1998; Carmines, McIver, and Stimson 1987).

In comparing the two sets of pairs we need to take into account a wrinkle occasioned by the survey design. Recall that G3 ranges in age and was older on average in 1997 than was G2 in 1965, which complicates comparisons between the two sets of pairs. To compensate for that, and to make a virtue out of variability, we distinguish two subsets of the G2-G3 pairs, those including children 16-20 years of age and those 24-28. The former have a mean age of 18, which equals that for G2 in 1965, and the latter a mean age of 26, which equals G2 as of 1973. As the headings in Table 1 make clearer, this enables a comparison between two sets of dyads, distinguished by whether the offspring were in their late teens or in their midtwenties. The G1-G2 pairs form an authentic panel whereas the G2-G3 pairs form a pseudopanel.

To assess pair correspondence, we regressed the child's score on the 10 core measures on the parent's score as of the same year. ${ }^{5}$ All of the measures were scaled to run from 0 to 1 . The unstandardized regression coefficients from these analyses, presented in Table 1, show how well the child's score tends to corresponds to the parent's score; a coefficient of 0 would indicate no correspondence and a coefficient of 1 would indicate perfect correspondence.

As Table 1 reveals, pair correspondence varies considerably across the measures. Our interest lies more in the comparison across generations, but it is worth noting that the highest concordance in both sets of pairs tends to be on objects that are more affect-laden and long-lived. Accordingly, measures involving partisanship, religion, and race lead the way. Perhaps the most inexplicable low relationship is that for political interest, especially when contrasted to the strong association evident on political knowledge,

\footnotetext{
${ }^{5}$ Specifically, we estimated a three-level random-effects model with pairs nested within families and within schools using restricted maximum likelihood estimation (Raudenbush and Bryk 2002). With the data were pooled across generations, the child's response was regressed on a dummy variable indicating the generational pairing (G1-G2 vs. G2-G3), the parent's response, and an interaction between the generational dummy and the parent's response. Only the coefficient representing the relationship between the parent's and the child's response is shown. See the online appendix for a discussion of why multilevel models were employed.
} 


\section{TABLE 1 Contemporaneous Parent-Child Correspondence. Comparing First and Second Generations with Second and Third Generations}

\begin{tabular}{|c|c|c|c|c|}
\hline & \multicolumn{2}{|c|}{ Youth in Late Teens } & \multicolumn{2}{|c|}{ Youth in Mid-20s } \\
\hline & $\begin{array}{c}\text { 1st and 2nd } \\
\text { Generations } \\
(1965)\end{array}$ & $\begin{array}{c}\text { 2nd and 3rd } \\
\text { Generations } \\
\text { (1997) }\end{array}$ & $\begin{array}{c}\text { 1st and 2nd } \\
\text { Generations } \\
\quad(1973)\end{array}$ & $\begin{array}{c}\text { 2nd and 3rd } \\
\text { Generations } \\
\text { (1997) }\end{array}$ \\
\hline Party Identification & .55 & .47 & .34 & .37 \\
\hline Presidential Vote Choice & .58 & .54 & .43 & .33 \\
\hline Racial Attitude & .32 & $.20^{\#}$ & .23 & .26 \\
\hline Opinion on School Prayer & .30 & .35 & .26 & .34 \\
\hline Business vs. Labor & .16 & .26 & .17 & $.38^{\star}$ \\
\hline Tolerance & .13 & .22 & .16 & .14 \\
\hline Political Trust & .17 & .10 & .05 & .07 \\
\hline Political Knowledge & .42 & - & .42 & - \\
\hline Interest in Politics & .11 & .18 & .10 & .15 \\
\hline Religiosity & .43 & $.62^{* *}$ & .37 & .39 \\
\hline
\end{tabular}

Note: In all but one case, entries were obtained from three-level random-effects analyses, with pairs nested within families and families nested within high schools, estimated using REML (Raudenbush and Bryk 2002). The exception was Political Knowledge, where data were not available for G3; there, a two-level model (G1-G2 pairs within schools) was estimated using GLS and the Swamy-Arora variance components estimator. Cell entries are the estimated effect (b) of the parent's response on the child's response, with each variable scaled $0-1$. Base Ns were 839 for the younger pairs and 925 for the older pairs, though the actual Ns in each analysis depended upon the extent of missing data. All coefficients are statistically greater than 0 , at $\mathrm{p}<.05$ or better, except those for political trust in columns 2, 3, and 4. Asterisks indicate whether the difference in the coefficients across generations is statistically significant, based on the $\mathrm{t}$-test for an interaction between the generational pairing (G1-G2 vs. G2-G3) and the parental attribute. ${ }^{*} \mathrm{p}<.10,{ }^{\star} \mathrm{p}<.05,{ }^{\star \star} \mathrm{p}<.01$ two-tailed.

and where we might expect higher consonance on the basis of family socioeconomic status alone. ${ }^{6}$

Table 1 enables a comparison of the two sets of generational pairs, the first one involving offspring in their late teens (columns 1 and 2). Not too surprisingly, the more recent pairs resemble the original ones in terms of what kinds of political attributes are most likely to be matched. Partisan attitudes and attitudes with a strong affective or moral component (e.g., racial and school prayer attitudes) are most likely to be passed on from parent to child, as are religious orientations. More surprisingly, in terms of hypotheses based on the declining solidity of the family, correspondence in the fresh pairs essentially equals or surpasses that found in the original pairs. The conclusion about intergenerational similarity in parent-child transmission is reinforced by a comparison of the dyads when the offspring were in their midtwenties (columns 3 and 4). Only one of the differences between the two sets of pairs reaches

${ }^{6}$ Because measurement unreliability will decrease the apparent level of parent-child disagreement (Dalton 1980), it can confound comparisons of transmission rates across measures. In order to diminish this confound, we tried to enhance and equalize the reliability of our indicators by building multi-item indices when possible. Nevertheless, the results of analyses that correct for measurement unreliability sustain the conclusions we draw in this section about the attributes most successfully transmitted from parent to child. See the online appendix. statistical significance (business vs. labor). To the extent that differences do occur, the more recent pairs tend to be more congruent than the older ones.

While a general pattern of similarity rather than difference characterizes transmission across generations, the few items on which differences do appear merit attention. There is little sign that parents are less important in shaping their offspring's partisan attachments in recent years, but there is evidence supporting the expectation that changing political contexts across generations can affect transmission levels. Consider the two political attributes having the greatest inter-generational discontinuity in transmission in Table 1: attitudes concerning race (greater for G1-G2, $\mathrm{p}=.07)$ and evaluation of business versus labor (greater for G2-G3, p <.05). The diminished correspondence on attitudes concerning race for G2-G3 relative to G1-G2 makes perfect sense given the changing nature of the political environment across the period (cf. Sears and Funk 1999). Racial issues, while not absent from the 1990s political agenda, had lost the center-stage they held in the 1960s. ${ }^{7}$

\footnotetext{
${ }^{7}$ Detailed analysis also shows that the transmission difference across generations is primarily limited to attitudes toward school integration, an issue that by the 1990s had lost salience. Attitudes about government assistance to blacks, by contrast, were at least as successfully transmitted in the later generation as in the earlier one.
} 
Conversely, the higher correspondence on evaluations of business versus labor reflects the greater significance of this dimension for politics in the 1980s and 1990s than for politics in the 1960s, as revealed by over-time analyses of data based on national samples (Stoker and Jennings 2008). Note also that the young G2-G3 pairs display more consonance on religiosity than do the young G1-G2 pairs $(p<.01)$. A more detailed and extensive analysis of the transmission of religious orientations across the two generations shows that this is because religious noninvolvement and secular beliefs are more faithfully transmitted in the more recent generation than in the older one. In any event, the political selves that parents convey to their children appear to reflect the salient political issues of the time.

Not surprisingly, contemporaneous correspondence tends to diminish over time in both sets of pairs. Columns 1 and 3 provide comparisons of the G1-G2 panel pairs as they "aged." Attributes displaying more than a modicum of parent-child agreement in 1965, aside from political knowledge, underwent a decline by 1973 . Those declines accord full well with theories (Erikson 1968; Mannheim [1928] 1972) and findings (e.g., Jennings 1989) about labileness during young adulthood. Such labileness should result in lowered parent-child agreement. Although based on a pseudo-panel, the G2-G3 data provide evidence of this as well (columns 2 and 4).

Data for the more recent pairs on the 10 additional measures not available in 1965 also bear on the replicability of family transmission patterns across the generations (online appendix Table A1). As with Table 1, congruence is highest on general orientations such as political ideology, though it is also very substantial on issues with a strong moral component such as gay rights, abortion, women's rights, and environmental concerns. Indeed, the strongest relationship across all 20 measures evaluated for G2-G3 occurred on the issue of abortion-.70. As expected, similarity on more abstract and less affect-laden topics tends to drop off and to be lower for the pairs involving offspring in their midtwenties than for the pairs involving youth in their late teens.

On balance, the patterns of political reproduction do not differ appreciably across the generations. In each generation, parents were most successful in passing along their general partisan orientations to their children. Indeed, parents were as successful in doing so as they were in transmitting their level of religiosity. They were modestly to markedly less successful on other political attributes. Still, on salient issues with a strong moral and/or affective compo- nent the transmission rates were quite high, sometimes approaching or even exceeding the rates found for general partisan orientations. In terms of the political views that they acquired from their parents, then, the 1965 high school graduates do not appear as sui generis. Their own children, socialized in a strikingly different social and political era, were about as likely as they were to follow in their parents' political, and religious, footsteps. These results indicate that while the content of what is passed on form parent to child is contingent on the sociopolitical nature of the times, the magnitude of the transmission is relatively impervious to those forces.

\section{Family Circumstances Enhancing Parent-Child Concordance}

Both theory and prior research suggest that family circumstances will influence the extent to which transmission is successful. In this section we evaluate two propositions derived from social learning theory about the circumstances under which transmission will be enhanced (Bandura 1969, 1986). Each focuses on the nature of the cues parents provide and builds on one of social learning theory's fundamental insights: that the success of observational learning depends on "the frequency, duration, rate, saliency, multiplicity, and complexity of modeling cues" (Bandura 1969, 222). The first proposition is that the transmission of political beliefs and attitudes from parents to children will, in general, be higher in more politicized family environments. Varying levels of politicization would be rough markers of the frequency and duration of cue giving on political issues in general. Political engagement on the part of the parents should generate more opportunities for signal giving, and hence, encourage more attention and learning on the part of the child. ${ }^{8}$ Similarly, low levels of parent politicization should leave the child either bereft or relatively open to influence from other socializing agents which, in turn, should discourage political consonance between parent and child.

A second proposition also derives from social learning theory's interest in the nature of modeling cues. In addition to the general salience of politics within the home, the consistency of parental cue

\footnotetext{
${ }^{8}$ This result would be undercut if two highly politicized parents disagreed with each other. However, both assortative mating and mutual socialization processes mean that parents are much more likely to agree than disagree with each other (Stoker and Jennings 2005).
} 
giving for any given sociopolitical attribute should increase the level of parent-to-child transmission rates (Bandura 1977, chap. 2). As public opinion research has shown, while most citizens tend to form reasonably durable views about the political parties, presidential candidates, and issues involving morality, religion, and race relations, individual differences in attitude strength and stability across issues are prevalent (e.g., Alwin, Cohen, and Newcomb 1991; Converse and Markus 1979; Sears 1983; Sears and Valentino 1997). Correspondingly, the consistency and, hence, clarity of cue giving should vary across individuals and political topics. Therefore, we expect observational learning, and hence transmission, to be most successful when the parents' political views are crystallized, stable, and communicated via consistent cues over long stretches of time.

To test the first proposition regarding the effects of family politicization, we built an index that combines information from the parents about their level of political engagement and information from the youth about the frequency of political discussion within their families (see appendix). To address the expectation regarding saliency and consistency of cue giving we constructed an index of the parent's response stability. For the G1-G2 analysis, parent responses from the 1982, 1973, and (when available) the 1965 waves were used to build an index, for each variable, indicating response stability across the period. Perfectly stable parents anchored one end of the index while parents with large fluctuations from wave to wave anchored the other. Although this measure relies on data gathered well after the child left the parent's home, we use it as an indicator of the consistency of signals while the child was being socialized. Our assumption is that the more stable the attitude from 1965 to 1982, the stronger the messages provided to the child in the 1950s and 1960s. We follow the same general procedure for the G2-G3 analysis, but here we gauge stability across the 1973-97 period for the Gen 2 parents, as they aged from 26 to 50 and reared the children that make up Gen 3.

We estimated the effects of each moderating variable simultaneously. Specifically, for each set of pairs, we estimated two-level (pairs within schools) random effects models that treated the youth's response as dependent and included five independent variables: the parent's response, family politicization (FP), and the product-interaction between the two, parent stability (PS), and the product interaction between parent stability and the parent's response:

$$
\begin{aligned}
\text { Youth }= & \beta_{0}+\beta_{1} \text { Parent }+\beta_{2} F P+\beta_{3} \text { Parent }^{\star} F P \\
& +\beta_{4} P S+\beta_{5} \text { Parent }{ }^{\star} P S+\varepsilon
\end{aligned}
$$

Entries shown in the table are derived from these results. The first and second columns show the predicted effect of the parent's response on the youth's response when family politicization is set to low (.1) and high (.9) values, respectively, holding parent stability to its mean level. The third and forth columns show the predicted effect of the parent's response on the youth's response when parent stability is set to low (.1) and high (.9) values, setting family politicization to its mean level. The results presented in Table 2 treat the G1-G2 pairs and Table 3 provides comparable results for G2-G3.

Turning first to the results based on politicization, we see rather limited effects on parent-child correspondence for generations 1 and 2 (Table 2, columns 1-2). Congruence typically increases under highly politicized environments, but only in the case of party identification, vote choice, political trust, and religiosity are these differences in the expected direction and statistically significant. Parent-child correspondence is actually diminished by higher family politicization on three measures, though not to a statistically significant extent. Further analysis shows that this pattern of lowered similarity is particularly strong, and statistically significant, with respect to attitudes about school integration, which is one component of the racial attitudes index. Limited correspondence on this issue arises because the youth gave more support to school integration than did their parents, especially if their family life was highly politicized. This finding most likely reflects the greater sensitivity of children in more politicized homes to the powerful period forces being exerted by the civil rights movement in the 1960s.

The results for the pairs from Generations 2 and 3 suggest a more substantial role for family politicization (Table 3, columns 1-2). Again, strong effects appear for party identification and vote choice. In these cases, transmission rates are spectacularly higher among the most politicized pairs. At the same time, the effects of family politicization also emerge for two of the issue-oriented measures in Table 3, school prayer and evaluations of business versus labor, and come close to attaining statistical significance for the third-racial attitudes. Moreover, effects of family politicization are evident on each of the ten supplemental variables analyzed for G2-G3 (Table A2, online). This group includes political ideology, as well as specific political attitudes regarding 
Table 2 Early Parent-Child Correspondence By Family Politicization and Parent's Stability. First and Second Generations (1965)

\begin{tabular}{|c|c|c|c|c|}
\hline & \multicolumn{2}{|c|}{ Family Politicization } & \multicolumn{2}{|c|}{ Parent's Stability } \\
\hline & Low & High & Low & High \\
\hline Party Identification & .44 & $.64^{\star}$ & .42 & $.57^{\star}$ \\
\hline Presidential Vote Choice & .45 & $.64^{\#}$ & .45 & $.59^{\#}$ \\
\hline Racial Attitude & .34 & .29 & .07 & $.42^{\star *}$ \\
\hline Opinion on School Prayer & .45 & .36 & -.05 & $.44^{* *}$ \\
\hline Evaluation of Business vs. Labor & .11 & .24 & .05 & $.23^{*}$ \\
\hline Tolerance & .05 & .17 & -.01 & $.16^{*}$ \\
\hline Political Trust & .06 & $.30^{*}$ & .19 & .18 \\
\hline Political Knowledge & .40 & .35 & .47 & .34 \\
\hline Interest in Politics & - & - & -.04 & $.16^{\star \star}$ \\
\hline Religiosity & .30 & $.54^{\star \star}$ & .27 & $.49^{* *}$ \\
\hline
\end{tabular}

Note: Results are based on a two-level random effects analysis, treating families as nested within schools, estimated using GLS with the Swamy-Arora variance components estimator. Each analysis (save that for Political Interest) included five independent variables, all scored 0-1: (1) the parent's score on the row variable, (2) Family Politicization (FP), (3) Parent Stability (PS), (4) the interaction between FP and the parent's row variable score, and (5) the interaction between PS and the parent's row variable score: Youth $=\beta_{0}+\beta_{1}$ Parent $+\beta_{2} F P+\beta_{3}$ Parent $^{*} F P+\beta_{4} P S+\beta_{5}$ Parent $^{*} P S+\varepsilon$. Entries shown in the table are derived from these results. The first and second columns show the predicted effect of the parent's response on the youth's response when Family Politicization is set to .1 (low) and .9 (high), respectively, holding PS to its mean level. The third and forth columns show the predicted effect of the parent's response on the youth's response when Parent Stability is set to .1 (low) and .9 (high), setting FP to its mean level. The Political Interest analysis excluded FP and the Parent Political Interest ${ }^{\star} F$ P interaction term (since Political Interest and FP are strongly related, both theoretically and empirically). Asterisks indicate the statistical significance of the relevant interaction coefficients. All coefficients are significantly greater than 0 , at $\mathrm{p}<.05$ or better, except those with absolute values of .12 or less. \#p $<.10,{ }^{\star} \mathrm{p}<.05$, ${ }^{* *} \mathrm{p}<.01$, one-tailed.

gay rights, abortion, the women's movement, environmentalists, the military, Vietnam, government job assistance, moral traditionalism, and limited government. Overall, then, families marked by parent political engagement and frequent political interchanges are families fostering the transmission of political attitudes and identities from parent to child.
Still, in many respects the differences in levels of parental stability produce the most striking effects (Tables 2-3, last two columns). As a general rule, when the parent's attitudes are unstable, transmission is weak or nonexistent. But when they are clear and consistently cued, transmission rates are high, often dramatically so. Among pairs characterized by high

TAble 3 Early Parent-Child Correspondence By Family Politicization and Parent's Stability. Second and Third Generations (1997)

\begin{tabular}{|c|c|c|c|c|}
\hline & \multicolumn{2}{|c|}{ Family Politicization } & \multicolumn{2}{|c|}{ Parent's Stability } \\
\hline & Low & High & Low & High \\
\hline Party Identification & .19 & $.73^{* * *}$ & .21 & $.42^{\star}$ \\
\hline Presidential Vote Choice & .20 & $.74^{\star *}$ & .29 & .44 \\
\hline Racial Attitude & .18 & .32 & .07 & $.30^{\#}$ \\
\hline Opinion on School Prayer & .26 & $.67^{\star}$ & .10 & $.45^{\star *}$ \\
\hline Evaluation of Business vs. Labor & .14 & $.70^{*}$ & .25 & .35 \\
\hline Tolerance & .21 & .17 & .00 & $.26^{* *}$ \\
\hline Political Trust & .05 & .28 & .13 & .12 \\
\hline Political Knowledge & - & - & - & - \\
\hline Interest in Politics & - & - & .00 & $.34^{\star * *}$ \\
\hline Religiosity & .37 & $.66^{\star}$ & .30 & $.51^{\star}$ \\
\hline
\end{tabular}

Note: See note to Table 3 for details concerning this analysis. 
levels of parental stability, correspondence levels regarding specific issues often approach the magnitude found for party identification and vote choice. Even when the differences in correspondence are not statistically significant, they typically are in the right direction and sizable in magnitude, with t-statistics approaching statistically significant levels.

Parental stability also influences correspondence in a number of cases where family politicization does not, including attitudes about race and tolerance for both sets of pairs, and views on school prayer and business versus labor for G1-G2. This patterning presumably reflects the importance of clear and consistent parental messages on political matters not ordinarily the subject of political conversation in the family. Whereas high levels of parental political engagement and family political discussion encourage parent-child consonance regarding traditional political objects such as the political parties and presidential candidates, or in attitudes on issues of heightened significance to the political controversies of the times, its effects are not always felt on more peripheral matters. In such cases, what is critical to parent-child transmission is whether the parent holds clear and consistent views. The results regarding politicization and racial attitudes for the G1-G2 pairs (Table 2) provide the most critical exception to this claim. Parental stability boosts transmission rates but family politicization does not because youths from politicized homes, especially conservative ones, were far more attuned to changing national tides ushered in by the civil rights movement.

Analyzing the subset of cases where data were available from both mother and father provides additional strong support for the proposition that the consistency of cue giving promotes reproductive fidelity. Parental couples were arrayed according to their degree of agreement on the measures discussed above. In all instances, across both sets of intergenerational families, the apparent impact of a parent's view on the child's view is diminished, sometimes by striking margins, if that view is challenged rather than reinforced by the spouse's view. As with stability of parental attitudes, this finding accords with expectations based on social learning processes. ${ }^{9}$

\footnotetext{
${ }^{9}$ For these analyses we created a dataset of mother-father-child triads from the 1965 study $(\mathrm{G} 1-\mathrm{G} 2, \mathrm{n}=430)$ and a second dataset of mother-father-child triads from the 1997 study (G2-G3, $\mathrm{n}=539$ ). At random, we designated one partner from each mother-father pair to serve as the "parent" and the other to serve as the "spouse" and then estimated a model that examined how well the child resembles the parent under varying circumstances of parent-spouse agreement. Further details and results are available upon request.
}

In sum, it is clear that family politicization and parental consistency are complementary, with each usually elevating the likelihood that children will adopt the political orientations of the parents. Successful transmission occurs less often when the family environment is apolitical and the parents have less consistent political (and religious) attributes; but similarity across generations is the norm when the home environment is politicized and when parents provide consistent signals about where they stand. These results demonstrate the explicitly political parental features under which the transmission model is likely to flourish and also show that the abetting conditions transcend distinctly different political eras. Both points provide strong support for a social learning perspective as applied to political socialization.

\section{Parent-Child Transmission: A Multivariate Assessment}

Although the foregoing results are persuasive from a social learning perspective, they probably overstate the extent to which children come to resemble their parents via the social learning and social influence processes integral to the transmission model. One reason is that parental opinions may reflect other parental and/or family attributes, such as socioeconomic status, that could also be driving the development of the child's political views. Another is that parental opinions will be related to the views of others in the child's environment, including peers, who may be influential. Finally, the bivariate model neglects youth attributes that may be influential and yet confounded with parental views. In this section we develop and estimate multivariate models to take these considerations into account.

\section{Parent and Child Attributes}

Children may resemble their parents via status inheritance and a shared social milieu, independently of transmission processes (e.g., Bengtson, Biblarz, and Roberts 2002; Dalton 1982). Children growing up in poor households, for example, may be drawn to the Democrats via their reputation as the party serving the poor and working class, regardless of their parents' point of view. To capture such dynamics, in the multivariate analysis we add measures of family income and parent education as well as dummy variables distinguishing fathers from working mothers 
and non-working mothers, a dummy variable indicating the parent's marital status, and a measure of the parent's use of newspapers and magazines to obtain political information.

The multivariate analysis also includes youth attributes that may be shaping their political orientations and be confounded with parental views. These attributes are the child's sex and race and three variables representing exposure to potential political influences outside the home: enrollment in civics class, level of organizational involvement, and the frequency of church attendance.

\section{Local Political Climates}

As recently and forcefully demonstrated by Campbell (2006) and Gimpel, Lay, and Schuknecht (2003) youth may be influenced by the political tendencies prevalent among their peers or in their local communities as well as by those of their parents. Illustratively, because liberal parents will tend to be more prevalent than conservative parents in liberal places, and vice versa, an analysis that fails to take into account local political climates will overstate the case for parental influence. Our multivariate analysis incorporates aggregate indicators of the political climates within the schools that the G2 youth respondents attended in 1965, using data from the 1965 Seniors Cohort Study (ICPSR study \#7575), which includes mass-administered questionnaire data from the entire senior class in 77 of the 97 sample schools $(\mathrm{N}=20,647){ }^{10}$

The contextual variables are Party Identification: the percent identifying as Republican minus the percent identifying as Democrat; Vote Preference: the percent preferring LBJ in 1964; Racial Attitude: the percent identifying "prejudice and discrimination against minority groups" as something that they were "least proud of as an American;" Political Tolerance: average score on tolerance index using same indicators as with G2; Political Trust: average score on trust index using same indicators as with G2; Political Interest: average response to political interest question also used with G2. As expected, correlations between these school climate variables and the corresponding parental attitude measures were positive, in the $.22-.34$ range. We also built school-level indicators of Religiosity: the percent attending church "almost

\footnotetext{
${ }^{10}$ In addition officials in all schools provided basic information such as school size, graduation rates, and school facilities. As described below and detailed in the appendix, we used both data sources to build school-level SES and political climate indicators.
}

every week" and Socioeconomic Status: a six-item index taking into account information about parental education and occupation as well as the students' anticipated education and occupation.

For all dependent variables but three the multivariate analysis includes the corresponding schoollevel political climate variable, as described above. The exceptions include evaluations of business vs. labor and political knowledge, for which there are no relevant school-level measure. As a proxy for the third exception, school prayer, we include schoollevel religiosity. Each analysis also includes the school-level SES indicator as well as dummy variables for region. Because the variation across schools that these contextual indicators gauge will mirror variation across the communities in which the schools are embedded, any estimated effects of high school climate may be due to influences operating in the local environment outside the school as well as those operating within it. The estimates are also vulnerable to selection bias confounds, but since we only include these variables in order to provide a stronger test of the transmission model and are not trying to draw substantive conclusions about contextual effects, we set aside the thorny issue of selection bias here.

\section{Results}

We proceed in two stages, beginning with the basic bivariate model that includes only the parent attribute as a predictor (column 1 in Table 4). We then add the parent, child, and contextual control variables. This strategy helps reveal how much of the initial estimate of parental influence remains after taking into account these alternative determinants of youth attributes (shown in column 2). Table 4 also displays the results for four of the variables most associated with socialization outcomes and usually seen as major rivals to the transmission model: parent education, family income, the school climate variable, and school-level SES.

As shown in Table 4, estimates of parent-child concordance are almost identical across the bivariate and multivariate models in five of the 10 cases-both where transmission levels are high (party identification, vote choice, and religiosity) and where they are low but reliable (evaluations of business vs. labor and political trust). This is so despite the fact that youth opinions also show strong associations with the contextual variables indexing the political and religious climates of their schools. Parental education and income also prove influential in a number of instances. 
TABle 4 A Multivariate Test of the Transmission Model. First and Second Generations

\begin{tabular}{|c|c|c|c|c|c|c|}
\hline \multirow[b]{2}{*}{$\begin{array}{l}\text { Dependent Variable: } \\
\text { (Youth Attributes) }\end{array}$} & \multirow{2}{*}{$\begin{array}{c}\text { Bivariate } \\
\text { Parent } \\
\text { Attribute }\end{array}$} & \multicolumn{5}{|c|}{$\begin{array}{l}\text { Multivariate Results on } \\
\text { Selected Variables }\end{array}$} \\
\hline & & $\begin{array}{c}\text { Parent } \\
\text { Attribute }\end{array}$ & $\begin{array}{c}\text { Parent } \\
\text { Education }\end{array}$ & $\begin{array}{l}\text { Family } \\
\text { Income }\end{array}$ & $\begin{array}{l}\text { School } \\
\text { Climate }\end{array}$ & $\begin{array}{c}\text { School } \\
\text { SES }\end{array}$ \\
\hline Party Identification $(\mathrm{n}=473)$ & $.55^{\star \star}$ & $.51^{\star *}$ & $.13^{*}$ & $-.14^{\#}$ & $.17^{\star \star}$ & .03 \\
\hline Vote Choice $(\mathrm{n}=395)$ & $.55^{\star *}$ & $.54^{\star \star}$ & .09 & $-.30^{*}$ & $.28^{*}$ & $.24^{\star}$ \\
\hline Racial Attitude $(\mathrm{n}=487)$ & $.31^{\star *}$ & $.21^{\star *}$ & -.02 & .00 & $.30^{\star *}$ & $.10^{\#}$ \\
\hline School Prayer $(\mathrm{n}=406)$ & $.32^{\star *}$ & $.21^{\star *}$ & -.02 & .13 & .09 & $-.38^{\star *}$ \\
\hline Business vs. Labor $(\mathrm{n}=485)$ & $.14^{\star *}$ & $.13^{\star *}$ & $.04^{\#}$ & $.10^{\star \star}$ & na & -.03 \\
\hline Political Tolerance $(\mathrm{n}=469)$ & $.12^{\star *}$ & .05 & $.15^{\star}$ & .00 & $.24^{*}$ & -.08 \\
\hline Political Trust $(\mathrm{n}=439)$ & $.14^{\star *}$ & $.13^{\star *}$ & $-.06^{\#}$ & -.04 & $.27^{\star *}$ & .07 \\
\hline Political Knowledge $(\mathrm{n}=475)$ & $.42^{\star *}$ & $.31^{\star *}$ & $.12^{*}$ & .08 & na & .11 \\
\hline Political Interest $(\mathrm{n}=474)$ & $.10^{\star *}$ & .04 & .06 & .01 & .05 & -.02 \\
\hline Religiosity $(\mathrm{n}=488)$ & $.43^{\star *}$ & $.39^{\star *}$ & -.02 & $-.17^{\star}$ & $.20^{\star *}$ & $-.09^{\#}$ \\
\hline
\end{tabular}

Note: Entries were obtained from two-level random-effects analyses, with pairs nested within high schools, estimated using GLS with the Swamy-Arora variance components estimator. Cell entries are the estimated effect (b) of the column variable on the child's response on the row variable, with each variable scaled $0-1$. Other predictors included in the multivariate analysis besides those shown in the table are dummy variables for region, parent marital status, sex of the parent, working status of the mother, parent media exposure, and child's race, sex, organizational involvement, church attendance, and exposure to civics courses. $\# \mathrm{p}<.10,{ }^{*} \mathrm{p}<.05$, ${ }^{* *} \mathrm{p}<.01$, one-tailed.

The multivariate analysis reveals transmission levels that are substantially lower than those evident in the bivariate analysis on three measures-racial attitudes, opinions on school prayer, and political knowledge. In each case, the coefficient on the parental attribute is diminished by about one-third but remains highly statistically significant. Contextual variables are at play with respect to racial attitudes and school prayer. In the former case, the primary confound is the local political climate, which is strongly associated with youth attitudes. Pair similarity on political knowledge is party driven by the higher knowledge levels attained among youth with highly educated parents.

In the two remaining cases, the low transmission levels evident in bivariate analysis disappear with the application of multivariate controls. Youth tolerance levels are better explained by parent education than by parent attitudes. By contrast, youth levels of political interest cannot be predicted on the basis of parent attributes, whether parent political interest or parent SES. This case is also unusual in showing no evidence of an influential local climate. The strongest predictor of the adolescents' political interest levels is how involved they are in clubs and organizations, both inside and outside of school (not shown).

All in all, these findings converge with previous work demonstrating that bivariate transmission findings tend to be preserved even when family social milieu is taken into account (Dalton 1982; Glass,
Bengston, and Dunham 1986; Jennings 1984; Tedin 1974; U.S. Department of Education 1999, 45-56). It follows that socialization models built only on demographic and structural features of the family will necessarily be incomplete. Not that children are typically subject to parental heavy-handed tuition. Rather, in the course of their development, children will be exposed to a variety of everyday cues and reinforcements from their parents that nudge them in the parental direction, net of a variety of other socialization vectors.

\section{The Long-Term Consequences of Family Transmission}

In the preceding sections we have demonstrated the trail of parental influence in the customary way, as indexed by the association between parental and offspring attitudes. Now we shift the focus, somewhat, to ask how early socialization experiences affect the offspring as they wend their way through life. Are patterns of adult political development influenced by the early acquisition of parental views? If children are at least partly the product of their parents' role as political socializers, then the degree of continuity among the socializees should represent the residue of parental influence over time.

Evaluating this expectation requires distinguishing parent-child dyads by the degree to which the 
child begins the journey through adulthood imbued with parental political attributes. Offspring who most resemble their parents initially should, according to this argument, exhibit more over-time persistence than those less like their parents. If no differences in persistence emerge, any argument about the importance of the early political socialization within the family would be seriously undermined. Those who derive their early political views from their parents would be indistinguishable from those whose early political views lack this parental grounding.

The design of the project makes possible such a test of parental influence. We have the initial parent-child agreement patterns as of 1965, which establish a baseline. Because of the four waves of observations on G2, we have three panel periods for purposes of calculating rates of individual-level stability. Thus, we can evaluate youth continuity from 1965 to 1973 (age 18-26), from 1973 to 1982 (age 26-35), and from 1982 to 1997 (age 35-50), comparing those who initially adopted their parent's view with those who did not. To estimate the degree of initial parent-child similarity we crosstabulated parent and child scores on each of the individual measures to be examined and divided them according to their level of correspondence (see appendix for the details). To gauge over-time correspondence, we calculated Pearson continuity correlations. ${ }^{11}$ The analysis is based on all 4-wave youth respondents for whom parent data were available in $1965(\mathrm{~N}=887)$.

Table 5 contains the results. Regardless of agreement level, stability tended to increase, often quite substantially, from the first panel period to the second, and then to change modestly from the second to the third. This pattern reflects the crystallization process as individuals move through young adulthood. Of more immediate relevance are the comparisons between the high and low correspondence groups. The results are a bit mixed, but two features stand out.

First, stability differences are most pronounced during the initial panel period, 1965-73. Adolescents who were initially most like their parents were more stable during this period, though only decidedly so in

\footnotetext{
${ }^{11}$ The findings in Table 5 (and Table 6, which also presents Pearson Rs) are very similar to those found when using OLS regression coefficients to gauge continuity.
}

seven out of the 10 cases. $^{12}$ The significance of this pattern derives from the fact that the eight years covered by the early panel represent a time of enormous change and challenge to young adults, including new endeavors, personal relationships, residential locations, and "adult-level" contact with the political world. Those young adults entering the time frame more securely attached to the political "apron strings" of their parents were more likely to withstand the novelties they were to encounter. Those less anchored in that way proved to be far more vulnerable, and thus more apt to change.

Second, the differences between the groups diminish and even sometimes reverse direction during the second and third panel periods. This development is almost completely a function of the much larger gains in stability among those starting out with lower levels of agreement with their parents. Apparently, the added years of political experience give this subgroup an additional basis for the strengthening and hardening of their political views. Of course, those in higher agreement with their parents also accumulated more political experience, but this increment came on top of a base already laid down by their more sustained pre-adult socialization as well as the higher levels of stability that they had already achieved between 1965 and 1973.

As a result, a different pattern of political development emerges across the groups according to the degree of initial parent/child correspondence. For those who exit childhood without having embraced their parents' views, the early years of adulthood are an especially critical period of political development. As they make the transition to adulthood, they tend to significantly revise their adolescent points of view. By contrast, those who leave childhood bearing the views of their parents show much more continuity across their late-teen to early-adult years. Though still adapting and growing over this period, they more often retain the views they inherited from their parents and articulated as adolescents.

\footnotetext{
${ }^{12}$ To evaluate the statistical significance of the difference between the continuity correlations across the low correspondence/high correspondence groups we used the nonparametric bootstrap procedure described by Davison and Hinkley (1997, especially $31-44,204-14)$. We iterated the resampling procedure 10,000 times for each pair of coefficients, and drew the p-values reported in Tables 5 and 6 from bootstrap-adjusted one-sided confidence intervals. The parametric alternative, the Fisher r-to-z transformation, requires (and is sensitive to violations of) bivariate normality (Cohen and Cohen 1983). Still, the bootstrap significance levels were very similar to those we obtained using the Fisher technique.
} 
TABle 5 The Stability of the Child's Political Orientations Over Time, By Level of Early Parent-Child Correspondence. First and Second Generations

\begin{tabular}{|c|c|c|c|c|c|c|}
\hline & \multirow{2}{*}{\multicolumn{2}{|c|}{$\begin{array}{c}\begin{array}{c}1965-1973 \\
\text { Continuity }\end{array} \\
\text { Correspondence }\end{array}$}} & \multirow{2}{*}{\multicolumn{2}{|c|}{$\begin{array}{c}\text { 1973-1982 } \\
\text { Continuity } \\
\text { Correspondence }\end{array}$}} & \multirow{2}{*}{\multicolumn{2}{|c|}{$\begin{array}{c}\text { 1982-1997 } \\
\text { Continuity } \\
\text { Correspondence }\end{array}$}} \\
\hline & & & & & & \\
\hline & Low & High & Low & High & Low & High \\
\hline Party Identification & .31 & $.54^{\star * *}$ & .63 & .66 & .57 & $.66^{*}$ \\
\hline Vote Choice & -.05 & $.38^{* * *}$ & .51 & .48 & .42 & .45 \\
\hline Racial Attitude & .15 & $.25^{\star}$ & .33 & .29 & .34 & $.48^{* *}$ \\
\hline School Prayer & .20 & $.39^{* *}$ & .54 & .55 & .59 & .55 \\
\hline Business vs. Labor & .24 & .22 & .44 & .47 & .53 & .56 \\
\hline Tolerance & .31 & $.40^{\star}$ & .53 & .56 & .57 & .59 \\
\hline Political Trust & .18 & .19 & .38 & .33 & .31 & .31 \\
\hline Interest in Politics & .31 & .31 & .39 & .46 & .50 & .50 \\
\hline Political Knowledge & .61 & $.79^{* * *}$ & .71 & $.84^{\star \star \star *}$ & .74 & $.80^{\star *}$ \\
\hline Religiosity & .47 & $.54^{\star}$ & .84 & .83 & .83 & .86 \\
\hline
\end{tabular}

Note: Entries are Pearson continuity correlations, calculated across the waves named at the top of the table. They are reported for two groups, distinguished on the basis of 1965 parent-child agreement levels. The low correspondence group includes respondents whose 1965 position did not closely match that their parent; Ns for this group vary from 108 to 525, depending upon the variable, but were held constant over time. The high correspondence group includes respondents whose 1965 position closely corresponded to that of their parent; Ns for this group vary from 169 to 640, depending upon the variable, and were also held constant over time. See Appendix for further details. Each analysis is based on G2 respondents for whom parent data were available in 1965, and who provided valid responses across all four waves of the study. All correlations are significantly greater than 0 , at $\mathrm{p}<.05$ or better, except that for vote choice across 1965-1973 in the low correspondence group (with an $\mathrm{R}=-.05$ ). Asterisks signify whether the correlations are significantly different across the low/high correspondence group. ${ }^{*} \mathrm{p}<.10,{ }^{* *} \mathrm{p}<.05,{ }^{* * *} \mathrm{p}<.01$, one-tailed.

Table 6 provides another way of looking at the long-term consequences of early socialization. Here, we examine over-time continuity in the two groups across the full 1965-97 period. Recall that as of 1997 the "children" were now 50 years old, and some 32 years beyond the initial recording of parent-child similarity. To what extent does the 50-year-old adult look like the 18-year-old adolescent? We gauge this over-time correspondence in both relative and absolute terms. Relative correspondence is indexed by a Pearson continuity correlation, calculated across the 1965-97 period. Absolute correspondence is indexed by the percentage of those taking the same, or a very similar, position in 1965 and 1997 (see appendix).

The pattern of findings in Table 6 reinforces what Table 5 demonstrated. Early acquisition of parental attributes has lifelong consequences. Relative continuity, or the extent to which one's position in 1997 can be predicted by one's position in 1965, is especially enhanced for basic partisan orientations, opinions toward school prayer, levels of political knowledge, and religiosity. Furthermore, on all but two items absolute continuity is significantly heightened among those who in 1965 had acquired their parents' views. ${ }^{13}$ Illustratively, $64 \%$ of the "wellsocialized" group retained their preadult party identification at age 50, compared with $55 \%$ of their "poorly socialized" counterparts. In this and most of the other cases found in Table 9, individuals bearing the trace of parental influence in 1965 showed higher levels of continuity well into middle age. This longitudinal evidence demonstrates the powerful, enduring effects of successful family transmission.

\section{Conclusion}

Our conclusions stem from an analysis of one set of parent-child pairs containing a youth cohort often dubbed the Protest Generation, and a second set containing the so-called Generation X. Notwithstanding the dramatic differences in family composition and life style, as well as the political environment characterizing their early socialization, the reproduction of

\footnotetext{
${ }^{13}$ The bootstrap procedure described in footnote 13 was used to calculate the statistical significance of the difference between the correlations. To test whether the differences in percentages were statistically significant, a chi-square test was used.
} 
Table 6 Relative and Absolute Continuity in Political Orientations from 1965-1997, By Level of Early Parent-Child Correspondence. First and Second Generations

\begin{tabular}{|c|c|c|c|c|}
\hline & \multirow{2}{*}{\multicolumn{2}{|c|}{$\begin{array}{c}\text { Relative Continuity, } \\
1965-1997 \\
\text { (Pearson Rs) } \\
\text { Correspondence }\end{array}$}} & \multirow{2}{*}{\multicolumn{2}{|c|}{$\begin{array}{c}\text { Absolute Continuity, } \\
1965-1997 \text { (\% } \\
\text { Taking Same Stance) } \\
\text { Correspondence }\end{array}$}} \\
\hline & & & & \\
\hline & Low & High & Low & High \\
\hline Party Identification & .18 & $.32^{\star *}$ & $54.6 \%$ & $64.4 \%{ }^{* *}$ \\
\hline Vote Choice & -.04 & $.32^{* * *}$ & $33.3 \%$ & $54.2 \% * * *$ \\
\hline Racial Attitude & .15 & .23 & $45.6 \%$ & $54.0 \%{ }^{* *}$ \\
\hline School Prayer & .04 & $.22^{\star \star}$ & $37.4 \%$ & $68.6 \% * * *$ \\
\hline Business vs. Labor & .10 & .20 & $38.0 \%$ & $39.0 \%$ \\
\hline Tolerance & .26 & .32 & $50.3 \%$ & $50.6 \%$ \\
\hline Political Trust & .16 & .17 & $16.4 \%$ & $22.8 \% \%^{* *}$ \\
\hline Interest in Politics & .26 & .33 & $45.0 \%$ & $55.7 \%{ }^{* * *}$ \\
\hline Political Knowledge & .57 & $.72^{\star * *}$ & $57.3 \%$ & $66.9 \%{ }^{* *}$ \\
\hline Religiosity & .45 & $.53^{\star}$ & $50.3 \%$ & $60.1 \%^{* * *}$ \\
\hline
\end{tabular}

Note: In the first pair of columns, entries are Pearson continuity correlations calculated across the 1965 and 1997 waves. They are reported for two groups distinguished on the basis of 1965 parent-child agreement levels. The low correspondence group includes respondents whose 1965 position did not closely match that of their parent; Ns for this group vary from 108 to 525 . The high correspondence group includes respondents whose 1965 position did closely correspond to that of their parent; Ns for this group vary from 169 to 640 . See Appendix for further details. All correlations are significantly greater than 0 , at $\mathrm{p}<.05$ or better, except those for vote choice and school prayer in the low correspondence group (with Rs of -.04 and .04, respectively). In the second pair of columns, entries indicate the percent of respondents taking the same position in both 1965 and 1997, again broken down by the degree of parentchild correspondence in 1965. Each analysis is based on G2 respondents for whom parent data was available in 1965, and who provided valid responses across all four waves of the study. Asterisks signify whether the correlations (1st set) or percentages (2nd set) are significantly different across the low/high correspondence groups. ${ }^{\star} \mathrm{p}<.10,{ }^{\star *} \mathrm{p}<.05,{ }^{\star * *} \mathrm{p}<.01$, one-tailed.

parental attributes was remarkably similar for these two sets of pairs. ${ }^{14}$ By uncovering parental attributes that affect parent-child transmission we demonstrated a fundamental, oft-neglected fact that is relevant to current public discourse concerning the political character of upcoming cohorts: parents can have an enormous degree of influence on the political learning that takes place in pre-adulthood. If parents are politically engaged and frequently discuss politics with the child, transmission rates rise substantially, particularly on topics of general political significance and salience. Regular political events such as campaigns and elections provide socialization opportunities for parents (Valentino and Sears 1998), as do more episodic events. Many parents obviously opt out of these opportunities, in part due to their own low levels of politicization.

Political reproduction across the generations occurs even more frequently when parental attitudes are reasonably consistent across time and between parents. On virtually all political (and religious)

\footnotetext{
${ }^{14}$ For very similar results based on a range of mainly nonpolitical variables see Bengston, Biblarz, and Roberts 2002, chap. 6).
}

topics, transmission rates rise when saliency and conviction are present. As a consequence, families will differ in what political commodities are being passed on. Most children may come to resemble their parents in one or another respect. But only if parents hold consistent attitudes on topics spanning the political agenda will children reproduce their parents' political character to a much broader extent. Selective political reproduction becomes, therefore, a likely outcome.

Obvious challenges to the social learning explanation for parent-child concordance rest in other family characteristics and the local sociopolitical context. For the most part, the transmission model proved to be remarkably robust against such challenges. At the same time, it is clear that other factors are sometimes at work, including parental education and income. What is more unusual is our demonstration of the indirect role played by parents in terms of situating the child in a given local sociopolitical environment, indexed here by the opinion climate and socio-economic status of the local high school. The independent effect of these two measures on several of our political measures provides a strong example of parental influence operating outside the transmission model. 
The legacy of parental influence also operates in a less obvious way. If children's political development is initiated by their parents, this should matter to how they develop subsequently. It does. Children who acquire political predispositions early in life from their parents are more stable in their early adulthood than are those who "leave home without it." Their predispositions, formed early, do persist. They carry that parental legacy forward, never fully losing the initial correspondence despite forces working to change them along the way. By contrast, those whose socialization in childhood is weak show much more instability well into their adult years. They exhibit a delayed pattern of political development, one where crystallized positions are slow to develop, one more susceptible to influences outside the childhood home.

Our results also speak to a new development in the study of political socialization. Social learning and status inheritance explanations for parent-child transmission have been challenged in recent years by studies of monozygotic and dizygotic twins, arguing that parent-child similarity on some political attitudes has a heavy genetic component (e.g., Alford, Funk, and Hibbing 2005, Martin et al. 1986). Although reservations have been raised regarding some of the assumptions guiding this path-breaking research (e.g., Beckwith and Morris 2008; Charney 2008), there is no blinking the findings themselves. In light of this challenge, testing expectations derived from social learning theory-as done here with measures of family politicization, consistency of parental cue giving, and persistence of early-acquired parental attitudes-assumes even more importance. Our affirmative findings in those respects are clearly compatible with a social mechanisms explanation. Nevertheless, it is possible that genetic mechanisms are doing at least some of the work. It remains for additional research to reconcile and perhaps integrate these two approaches to understanding parent-child concordance.

One substantive area included in our analysis has particular relevance for students of electoral behavior and political parties. An early and abiding focus found in studies of political socialization has been that of partisan orientations, which play a central role in affecting electoral outcomes and organizing issue stances. The formation of these orientations thus assumes importance. Spanning three generations and over three decades, our results demonstrate the continuing centrality of partisanship as an outcome of familial socialization. Children adopt parental partisan orientations more so than any other political characteristics. They tend to identify with the same party and to vote in a comparable fashion. The high levels of concordance found for partisan orientations compare favorably with those for levels of religiosity, as indexed by frequency of church attendance and beliefs about the inerrancy of the Bible. Parents are expected to exert a powerful influence on the religious practices and beliefs of their children. That they exert a similar level of influence on the child's partisan predispositions, which are presumably less central to overall character development, is both striking and significant, not least because it helps sustain a commitment to partisanship and a competitive two-party system.

Our overall results raise two particularly intriguing questions. We have traced the lagged effects of parental views that the youth were exposed to as adolescents, which provides a sense of how the initial parental legacy persists. Parents, however, do not stop being parents when the child reaches age 18, and may continue to influence the child in subsequent years. And the offspring, no longer "children," may be exerting influences on the parent in turn. This dynamic remains to be analyzed carefully. Parents may be influencing their adult children and vice versa. Alternatively, attributes that the two share, such as socioeconomic status or partisan identification, may be shaping in parallel fashion the development of attitudes on new, or newly salient, issues. This scenario suggests a more complex model of parental influence, one wherein parents inculcate basic orientations, which then influence responses to subsequent political stimuli.

A second intriguing question involves the interaction between politicization within the family and the political climate while the child is still at home. We noted in passing that adolescents emerging from highly politicized homes in 1965 less often adopted the parental position on school integration than did adolescents from apolitical homes. This finding reflects the susceptibility of the politicized children to broader political forces at work, in that they were more likely to reject the anti-integration position commonly expressed by their parents than were children from less politicized homes. On the one hand, then, having a politicized family environment typically encourages the child to learn from the parent and to adopt the parent's views. On the other hand, it also leaves the child more attuned to outside political influences. In periods of upheaval like those of the mid-1960s, or in general when the political environment contains forces antithetical to parental inclinations, this politicization may work against within-family congruence. Understanding how political engagement plays out in such cases, and tracing its 
implications for aggregate intergenerational change, constitutes another important challenge for future research.

\section{Appendix}

\section{Additional Information on Question Wording and Index Construction}

All variables reported on here and in the text were coded to range from 0 to 1 .

Presidential Vote Choice. For 1965: vote (G1) or preference (G2) in the 1964 presidential election. For 1997: an index combining vote for President in 1992 and in 1996 (with one missing value allowed).

Racial Attitude. An index averaging two component variables (with one missing value allowed). For G1-G2: (1) attitude toward school integration and (2) the relative evaluation of whites vs. blacks. For G2-G3: (1) attitude toward school integration and (2) attitude toward government assistance for blacks. School Integration: A 3-point scale coded 0 for "Washington should see to it that white and black children go to the same schools" .5 for "depends" and 1 for [Washington should] "stay out of the area as it is none of its business." Evaluation of Whites-Blacks: Difference between the feeling thermometer score for whites and the score for blacks. Aid to Blacks: A 7point scale, with endpoints: "the government in Washington should make every possible effort to improve the social and economic position of blacks and other minority groups" versus "the government should not make any special effort to help minorities because they should help themselves."

Opinion on School Prayer. A 3-point scale coded 1: "schools should be allowed to start each day with a prayer," .5 "depends" or 0 "religion does not belong in the schools."

Evaluations of Business versus Labor. Difference in evaluations of "Big Business" and "Labor Unions" on a $0-100^{\circ}$ feeling thermometer scale.

Tolerance. An index combining responses to two agree/disagree questions: (1) "If someone wanted to make a speech in this community against churches and religion, that person should be allowed to speak." (2) "If a Communist were legally elected to some public office around here, people should allow that person to take office."

Family Politicization (Tables 3-4). An index formed by averaging two components. (1) Parent's political engagement, the number of "yes" responses to six questions about political participation: working for a party, issue, or candidate; attempting to persuade others during election campaigns; attending meetings, rallies, or dinners; displaying campaign buttons or stickers; giving money for campaigns; and voting in the most recent presidential election. (2) Frequency of political discussion in the family, as reported by the child. In 1965: Do you talk about public affairs and politics with members of your family?" (If Yes) "How often would you say that is-several times a week, a few times a month, or once or twice a year?" In 1997: "How often do you and your parents talk about any kind of public affairs and politics, that is, anything having to do with local, state, national, or international affairs?" Response options were "very often," "pretty often," "not very often," and "never."

Parent's Stability (Tables 3-4). Each variable was created in four steps. First, we computed the absolute differences of responses between adjacent waves of the survey. Second, we calculated the average of those absolute difference scores, across 65-73 and 73-82 for G1, and across 73-82 and 82-97 for G2. Third, we recoded extremely unstable individuals (defined as having $\mathrm{z}$-scores $>3.0$ on the index formed from steps 1 and 2), if any, to the next lowest score found on the variable. This was done to reduce the leverage of outliers on the analysis. Finally, we scaled the variable to range from 0 (completely stable) to 1 (maximal instability, caveat from step 3 aside).

Control Variables used in Multivariate Analysis (Tables 4, 7). School climate variables: See description in the text. School-level SES: An index using (1) $\%$ of high school seniors going on to college (schoolreported), (2) mother's education and (3) father's education (\% at least some college minus \% less than high school), (4) average father's occupation Duncan decile code, (5) \% of seniors anticipating going on to college after high school, (6) average anticipated occupation Duncan decile code. Each variable was first standardized before averaging the index components. Family Income: Respondents in each income category were first assigned an income in dollars equal to the category midpoint. The 1965, 1973, and 1982 scores were transformed into 1997 dollars by adjusting for inflation using the average CPI figures obtained from ftp://ftp.bls.gov/pub/special.requests/ cpi/cpiai.txt, and then rescaled to range from 0 (no income) to 1 (highest income in 1997 dollars).

Parent-Child Correspondence (Tables 5-6). A dichotomous variable, distinguishing pairs by the 
similarity of parent and child responses. In the "high correspondence" group, the parent and child had the same response on the variable in question or, in two cases, an absolute difference of .05 or less (attitude toward blacks and business versus labor). For PID, the high correspondence group included those who articulated the same party preference or leaning.

1965-1996 Absolute Continuity (Table 6). The 1965 and 1997 variables were first recoded, if necessary, to create a meaningful number of distinct categories. Then, people were categorized as stable or unstable on the basis of whether they gave the same or different responses in 1965 and 1997. The business versus labor variable was first recoded into a 3-point scale (collapsing 0-. 44, .45-. 55, and .56-1), as was the scale tapping attitudes toward blacks and the index of religiosity. The original political trust and political knowledge scales were also collapsed into three point scales by combining the two low, the two middle, and the two high categories. On party identification, people were categorized as giving the same response if they expressed the same partisan preference or leaning, or lack thereof, in 1965 and 1997.

\section{Acknowledgments}

Financial support for the most recent data collection utilized here came from the National Science Foundation, Grant SBR -960-1295. We are also grateful for the technical assistance of Kuang-hui Chen and Jackie Bass and the financial support provided by the Academic Senate of the University of California, Santa Barbara, and the Institute for Governmental Studies, University of California, Berkeley.

Manuscript submitted 30 May 2008

Manuscript accepted for publication 22 November 2008

\section{References}

Abramowitz, Alan I., and Kyle L. Saunders. 1998. "Ideological Realignment in the U.S. Electorate." Journal of Politics 60 (2): 634-52.

Acock, Alan C., and Vern L. Bengston. 1980. "Socialization and Attribution Processes: Actual Versus Perceived Similarity among Parents and Youth." Journal of Marriage and the Family 42 (2): 501-15.

Alford, John R., Carolyn L. Funk, and John R. Hibbing. 2005. "Are Political Orientations Genetically Transmitted?" American Political Science Review 99 (2): 154-67.

Alwin, Duane F., Ronald L. Cohen, and Theodore M. Newcomb. 1991. Political Attitudes over the Life Cycle: the Bennington Women after Fifty Years. Madison: University of Wisconsin Press.
Bandura, Albert. 1969. "Social-Learning Theory of Identificatory Processes." In Handbook of Socialization Theory Research, ed. David A. Goslin. Chicago: Rand McNally, 213-62.

Bandura, Albert. 1986. Social Foundations of Thought and Action. Englewood Cliffs, NJ: Prentice Hall.

Beckwith, Jon, and Corey A. Morris. 2008. "Twin Studies of Political Behavior: Untenable Assumptions?" Perspectives on Politics 6 (4): 785-91.

Bengston, Vern L., Timothy J. Biblarz, and Robert E. L. Roberts. 2002. How Families Still Matter: A Longitudinal Study of Youth in Two Generations. Cambridge: Cambridge University Press.

Campbell, David E. 2006. Why We Vote: How Schools and Communities Shape our Civic Life. Princeton, NJ: Princeton University Press.

Carmines, Edward G., John P. McIver, and James A. Stimson. 1987. "Unrealized Partisanship: A Theory of Dealignment." The Journal of Politics 49 (1): 376-400.

Charney, Evan. 2008. "Genes and Ideologies." Perspectives on Politics 6 (2): 299-319.

Cohen, Jacob, and Patricia Cohen. 1983. Applied Multiple Regression/Correlation Analysis for the Behavioral Sciences. 2nd ed. Hillsdale, NJ: Lawrence Erlbaum Associates.

Converse, Philip E., and Gregory B. Markus. 1979. "Plus Ca Change... : The New CPS Election Study Panel." American Political Science Review 73 (1): 32-49.

Dalton, Russell. 1980. "Reassessing Parental Socialization: Indicator Unreliability versus Generational Transfer." American Political Science Review 74 (2): 421-31.

Dalton, Russell. 1982. "The Pathways of Parental Socialization." American Politics Quarterly 10 (2): 139-57.

Davison, A. C., and D. V. Hinkley. 1997. Bootstrap Methods and their Application. New York: Cambridge University Press.

Erikson, Erik H. 1968. Identity: Youth and Crisis. New York: Norton.

Gimpel, James G., J. Celeste Lay, and Jason E. Schuknecht. 2003. Cultivating Democracy: Civic Environments and Political Socialization in America. Washington, DC: Brookings Institute.

Glass, Jennifer, Vern L. Bengtson, and Charlotte Chorn Dunham. 1986. "Attitude Similarity Three Generation Families: Socialization, Status Inheritance, or Reciprocal Influence?” American Sociological Review 51 (5): 685-98.

Jennings, M. Kent. 1984. "The Intergenerational Transfer of Political Ideology in Eight Western Nations," European Journal of Political Research 12 (3): 261-76.

Jennings, M. Kent. 1989. "The Crystallization of Orientations." In Continuities in Political Action, eds. M. Kent Jennings, Jan van Deth, et al. Berlin: Walter de Gruyter, 313-48.

Jennings, M. Kent, and Richard G. Niemi. 1968. "The Transmission of Political Values from Parent to Child. American Political Science Review 62 (1): 169-84.

Jennings, M. Kent, and Richard G. Niemi. 1974. The Political Character of Adolescence. Princeton, NJ: Princeton University Press.

Mannheim, Karl. [1928] 1972. "The Problem of Generations.” In Essays on the Sociology of Knowledge, ed. P. Keckemeti. London: Routledge \& Kegan Paul, 276-320.

Martin, N. G., L. J. Eaves, A. C. Heath, Rosemary Jardine, Lynn M. Feingold, and H. J. Eysenck. 1986. "Transmission of Social Attitudes." Proceedings of the National Academy of Sciences of the United States of America 83: 4364-68.

Miller, Warren E., and J. Merrill Shanks. 1996. The New American Voter. Cambridge, MA: Harvard University Press. 
Percheron, Annick, and M. Kent Jennings. 1981. "Political Continuities in French Families: A New Perspective on an Old Controversy." Comparative Politics 13 (3): 421-36.

Raudenbush, Stephen W., and Anthony S. Bryk. 2002. Hierarchical Linear Models: Applications and Data Analysis. 2nd ed. Thousand Oaks, CA: Sage.

Sears, David O. 1983. "The Persistence of Early Political Predispositions: the Roles of Attitude Object and Life Stage." In Review of Personality and Social Psychology, vol. 4, ed. Ladd Wheeler and Paul Shaver. Beverly Hills, CA: Sage Publications, 79-116.

Sears, David O., and Carolyn Funk. 1999. "Evidence of the LongTerm Persistence of Adults' Political Predispositions" Journal of Politics 61 (1): 1-28.

Sears, David O., and Nicholas A. Valentino. 1997. "Politics Matters: Political Events as Catalysts for Preadult Socialization." American Political Science Review 91 (1): 45-65.

Stoker, Laura, and M. Kent Jennings. 2005. "Political Similarity and Influence between Husbands and Wives." In The Logic of Politics: Personal Networks as Contexts for Political Behavior, ed. Alan S. Zuckerman. Philadelphia: Temple University Press, 51-74.

Stoker, Laura, and M. Kent Jennings. 2008. "Of Time and Partisan Polarization." American Journal of Political Science 52 (3): 619-35.

Tedin, Kent L. 1974. "The Influence of Parents on the Political Attitudes of Adolescents." American Political Science Review 68 (4): 1579-92.

Tedin, Kent L. 1980. "Assessing Peer and Parent Influence on Adolescent Political Attitudes." American Journal of Political Science 24 (1): 136-54.
Tims, Albert R. 1986. "Family Political Communication and Social Values." Communication Research 13 (1): 5-17.

U.S. Department of Education, National Center for Education Statistics. 1999. The Civic Development of 9th-Through 12thGrade Students in the United States:1996, NCES 1999-131 (Ed. Richard G. Niemiand Chris Chapman). Washington, DC.

Valentino, Nicholas, and David O. Sears. 1998. "Event-Driven Political Socialization and the Preadult Socialization of Partisanship." Political Behavior 20 (2): 127-54.

Westholm, Anders. 1999. "The Perceptual Pathway: Tracing the Mechanism of Political Value Transfer across Generations." Political Psychology 20 (3): 525-52.

Westholm, Anders, and Richard G. Niemi. 1992. "Political Institutions and Political Socialization." Comparative Politics 25 (1): 25-41.

M. Kent Jennings is professor of political science, University of California, Santa Barbara, Santa Barbara, CA 93106.

Laura Stoker is associate professor of political science, University of California, Berkeley, Berkeley, CA 94720.

Jake Bowers is assistant professor of political science, University of Illinois, Urbana-Champaign, Urbana, IL 61801. 